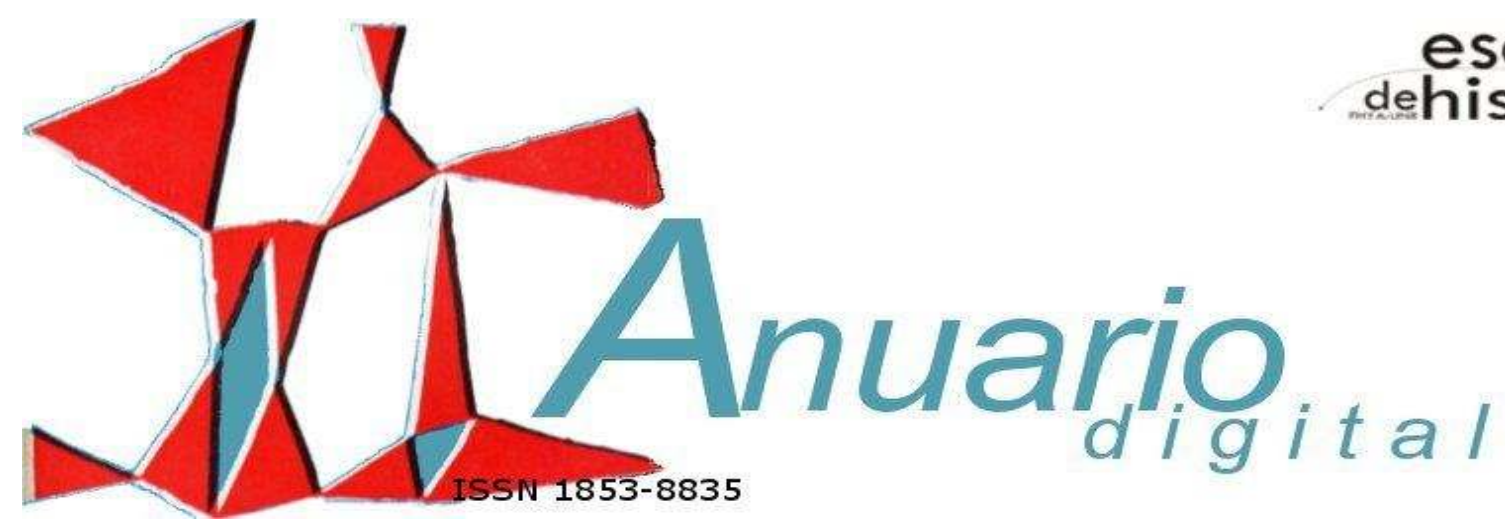

\title{
SOURRIÈRE DE SOUILLAC, UN MATEMÁTICO ILUSTRADO EN EL RÍO DE LA PLATA. SU TRAYECTORIA Y APORTES A LA MONARQUÍA BORBÓNICA A FINES DEL SIGLO XVIII.*
}

\author{
MARTÍN ALEJANDRO GENTINETTA** \\ (Universidad Nacional de Córdoba - CONICET); \\ mgentinetta@ffyh.unc.edu.ar
}

RESUMEN

Este trabajo reconstruye algunos rasgos relevantes de la trayectoria de Joseph Sourrière de Souillac, un maestro de matemáticas con una extensa trayectoria al servicio de la Monarquía española que transcurre, en particular, en el Virreinato del Río de la Plata. La formación y las actividades desempeñadas por Sourrière de Souillac muestran a un funcionario que participó de los movimientos ilustrados que tuvieron curso en la península y en Hispanoamérica; lo cual permite reflexionar sobre la utilización por parte del reformismo borbónico de los conocimientos científicos de la época.

Palabras clave: "ciencias útiles" - Imperio español - Siglo XVIII - Sourrière de Souillac - Virreinato del Río de la Plata

\footnotetext{
* Una primera versión de este trabajo fue presentada y discutida en las $V$ Jornadas Experiencias de la Diversidad y IV Encuentro de discusión de avances de investigación sobre Diversidad Cultural, Rosario (Argentina), agosto de 2012. Agradezco los comentarios recibidos en esa oportunidad.

** Cátedra de Historia Moderna, Escuela de Historia, Facultad de Filosofía y Humanidades, Universidad Nacional de Córdoba; CONICET.
} 
ABSTRACT

Sourrière de Souillac, an Enlightment Mathematic in the Río de la Plata. His career and contributions to the Borbonic

Monarchy

This paper deals on some important aspects of Joseph Sourrière de Souillac life. Sourrière, a Mathematic teacher, served the Spanish monarchy, specially in the Virreinato del Río de la Plata during many decades. His education and his activities developed in Spain and afterwards in South America shows Sourrière as a member of the Spanish Enlightenment movement. The aim of this paper is to considerer the importance of scientific knowledge to Borbonic politics, analyzing Sourrière's activities in this field.

Key words: «useful sciences» - Spanish Empire - Eighteenth century - Sourrière de Souillac - Virreinato del Río de la Plata

\section{Introducción}

Este trabajo reconstruye la vida y trayectoria de Joseph Sourrière de Souillac, un maestro de matemáticas que residió durante casi cuarenta años en Buenos Aires, entre fines del siglo XVIII y principios del XIX. Su figura se conoció a partir de que Pedro De Angelis publicó unos años después de su muerte algunos de sus manuscritos en la compilación Obras y Documentos relativos a la Historia Antigua y Moderna de las Provincias del Río de la Plata. En esa conocida obra, De Angelis incluyó dos escritos de Sourrière: "Itinerario de Buenos Aires a Córdoba" (1784) y "Descripción geográfica de un nuevo camino de la Gran Cordillera para facilitar las comunicaciones de Buenos Aires con Chile" (1805). ${ }^{1}$ Éstos estuvieron acompañados de una breve contextualización, a la que De Angelis añadió unos pocos datos biográficos de su autor.

Interesados en profundizar en la trayectoria y aportes de este matemático, hallamos en el Archivo General de la Nación (AGN) de Buenos Aires varios expedientes relacionados con Sourrière. Uno de ellos contenía documentos sobre su formación científica y de algunas de sus actividades desarrolladas en la capital virreinal. Otros, estaban relacionados con la expedición para abrir un camino por tierra entre Buenos Aires y Chile e incluían, además, los diarios autógrafos de Sourrière. Parte de esos diarios habían sido los ya

\footnotetext{
${ }^{1}$ De Angelis, Pedro; Colección de Obras y Documentos relativos a la Historia Antigua y Moderna de las Provincias del Río de la Plata; Imprenta del Estado; Buenos Aires; 1837; T. VI.
}

174

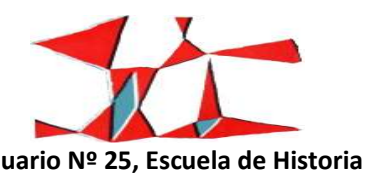

Revista Digital № 4, Facultad de Humanidades y Artes, Universidad Nacional de Rosario, 2013

ISSN 1853-8835 
publicados por De Angelis. Sin embargo, al cotejar esa versión con los datos originales encontramos que muchas entradas no eran coincidentes: así por ejemplo, para un mismo día lo anotado por Sourrière y lo publicado por De Angelis era diferente.

A partir del hallazgo de esta nueva información, nuestro objetivo se orienta a ampliar y enriquecer la lectura sobre la trayectoria y las contribuciones de este matemático. Asimismo, la reconstrucción de su vida nos posibilita recuperar algunos rasgos del escenario político-cultural del Virreinato del Río de la Plata. Éstos se relacionan con el estudio y fomento de las ciencias matemáticas en el siglo XVIII y cómo estos saberes fueron herramientas cuyo desarrollo favoreció la Monarquía. Durante todo el setecientos encontramos distintos personajes cuyas actividades y formación son ejemplos a través de los cuales se pueden recuperar los esfuerzos de la Corona por favorecer la modernización de los estudios científicos, en particular aquellos nuevos saberes relacionados con la revolución científica iniciada en el siglo XVII. Buena parte de estos actores fueron funcionarios borbónicos que contaban en su haber con una significativa preparación, al tiempo que estaban familiarizados con los saberes y avances que venían generándose dentro del mundo científico desde hacía más de un siglo. Creemos entonces que un cuidadoso análisis biográfico de un personaje como Sourrière de Souillac contribuye a un conocimiento más completo de estos temas.

\section{Los Borbones y el fomento de las «ciencias útiles»}

Felipe de Anjou, luego conocido como Felipe V, llegó al trono hispánico en 1700, en medio de un conflicto bélico que se extendió durante más de una década, la Guerra de Sucesión Española. Desde el comienzo de su reinado el joven monarca favoreció el desarrollo de un extenso y complejo proceso de reformas, que fueron continuadas por sus sucesores durante el setecientos. El objetivo principal de estas reformas se orientó a transformar las estructuras político-económicas de la Monarquía con las que se buscó recuperar la antigua hegemonía que ésta había alcanzado en el siglo XVI. En este contexto de reformas, la redefinición de los vínculos entre la Corona y sus Reinos de Indias, tanto en los modos de administrarlos como en los mecanismos para relacionarse con ellos, ocupó un lugar destacado entre las preocupaciones y urgencias de los Borbones.

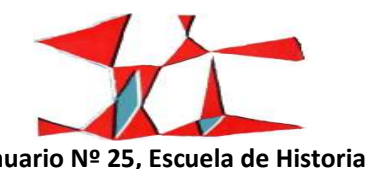


Las políticas reformistas que fue construyendo la Monarquía se desenvolvieron en espacios heterogéneos, tanto en el ámbito peninsular como en el hispanoamericano. Si bien hubo una gran disparidad de propuestas para dar soluciones a múltiples problemáticas que afectaban a los distintos territorios de la Monarquía, puede advertirse que buena parte de las reformas compartían un marco común delimitado por las ideas ilustradas, ${ }^{2}$ en donde se destacaba el pensamiento racional y las herramientas provistas por la ciencia moderna. En este sentido, de acuerdo a algunos especialistas, los Borbones impulsaron un modelo de actividades científicas que estuvo en buena parte determinado por las consecuencias de la Guerra de Sucesión. La necesidad de políticas dirigidas a atender la vertebración interior de la Monarquía y la defensa de la integridad de sus posesiones ultramarinas imprimieron un marcado carácter imperial a la dinámica de la ciencia española en el siglo XVIII. Ésta se convirtió entonces en un instrumento de reformas de la Monarquía y sus actores en agentes gubernamentales. ${ }^{3}$

En el amplio espectro de las ciencias, fueron las llamadas «ciencias útiles», es decir las matemáticas, la química, la física, la astronomía, la botánica, por nombrar alguna de las más importantes, las que recibieron un fuerte estímulo con las políticas borbónicas. Si bien el siglo XVIII, -afirma Gómez Urdáñez-, fue el siglo de la filosofía, de la medida y de la experimentación, y también el de un marcado utilitarismo y mecenazgo entusiasta de los gobiernos, no todas las monarquías favorecieron proyectos de largo plazo que tuviesen como centro la investigación pura y la creación de una infraestructura técnica. Para la Monarquía Hispánica, el impulso científico tenía el claro objetivo de contrarrestar deficiencias técnicas puntuales y se orientó a transformar los principales motores del siglo: la marina, la artillería, las necesidades materiales de la corte y de las elites sociopolíticas.

\footnotetext{
${ }^{2}$ Preferimos emplear el término "ideas ilustradas" antes que el nombre, con mayúscula, de llustración. Los estudios de las últimas décadas sostienen que en el caso hispánico nos encontramos frente a un conjunto de ideas y creencias heterogéneas, que a lo largo del siglo XVIII no se aglutinaron en una propuesta programática única dotada de objetivos precisos y cuyos representantes, aún coincidiendo con ciertas premisas, mantuvieron importantes diferencias entre sí. De allí que optamos por emplear términos como "ideas ilustradas", "ilustrados borbónicos" o incluso "corrientes ilustradas". Véase Ruiz Torres, Pedro; Historia de España. Reformismo e llustración; V. 5; Crítica-Marcial Pons; Barcelona; 2008; cap. 6.

${ }^{3}$ Lafuente, Antonio; de la Sota, José y Vilchis, Jaime; "Dinámica imperial de la ciencia: los contextos metropolitano y colonial en la cultura española del siglo XVIII"; en Guimerá, Agustín; El reformismo borbónico. Una versión interdisciplinar; Alianza; Madrid; 1996; p.181.
}

176

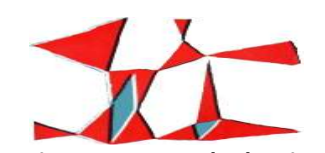

Anuario № 25, Escuela de Historia

Revista Digital № 4, Facultad de Humanidades y Artes, Universidad Nacional de Rosario, 2013 ISSN 1853-8835 
El principal interés residía en la aplicación práctica de herramientas y recursos científicos a sectores estratégicos, de los que se esperaba un beneficio inmediato. ${ }^{4}$ Esta orientación de las ciencias al servicio del poder político de la Monarquía, y en particular de sus necesidades militares, fue un fenómeno que Lafuente y Peset llamaron "militarización de la ciencia", puesto que la casi totalidad de las actividades científicas estuvo vinculada jurídica y financieramente, y de modo directo o indirecto, a los cuerpos armados de la Monarquía. ${ }^{5}$ La Marina y el Ejército fueron así, dos de sus pilares básicos y las instituciones que constituyeron el epicentro de la renovación científica. Ésta adoptó diferentes formas: creación de academias, apertura de cátedras de "ciencias útiles", envío de pensionarios a centros del exterior para su mejor instrucción, el desarrollo de prácticas de espionaje científico y la contratación de científicos y técnicos extranjeros, entre otras estrategias.

Esta simbiosis entre el campo militar y el científico puso a disposición de la Monarquía profesionales expertos en la resolución de problemáticas puntuales dentro de sus territorios que, al mismo tiempo, se desempeñaban como funcionarios reales abocados a la obtención de información y confección de diferentes representaciones de la realidad (mapas, catálogos, colecciones, etc.). ${ }^{6}$ Las reflexiones filosóficas y políticas quedaron relegadas a un segundo plano entre estos funcionarios, no así aquellas cuyo epicentro fue la economía, pues la identificación de las causas del atraso económico y los caminos para su superación de la península estuvieron entre sus las prioridades.

La opción de favorecer el desarrollo científico en estrecha colaboración con las instituciones militares también hay que situarlo en las resistencias que encontraron los Borbones en sus intentos de reformar la estructura de las universidades. Los proyectos de cambios en los planes de estudio, de fomentar la apertura de nuevas cátedras y la incorporación de los saberes científicos, no tuvieron una acogida favorable. Los claustros universitarios, las Órdenes religiosas que dirigían las casas de estudio y los Colegios

\footnotetext{
${ }^{4}$ Gómez Urdáñez, José Luis; “Antes de los Delhuyar: la promoción política de la ciencia en España”; en Ibáñez Rodríguez, Santiago (coord.); La proyección mundial de los hermanos Delhuyar en el campo de la ciencia y la economía; Universidad de La Rioja; Logroño; 2002; pp. 33-34.

${ }^{5}$ Lafuente, Antonio y Peset, José Luis; "Las actividades e instituciones científicas en la España Ilustrada"; en Sellés, Manuel; Lafuente, Antonio y Peset, José Luis (comps.); Carlos III y la ciencia de la Ilustración; Alianza; Madrid; 1988; pp. 39-41.

${ }^{6}$ Lafuente, Antonio y Valverde, Nuria; Los mundos de la ciencia en la llustración española; Fundación Española para la Ciencia y la Tecnología; Madrid; 2003; p. 14.
}

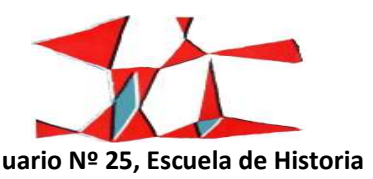


Mayores se opusieron a esos proyectos. ${ }^{7}$ Esa es una de las razones que explica la necesidad de encontrar otras vías para la difusión del pensamiento científico moderno en España. Las Academias y las cátedras de matemática, física, química, cirugía y otras dentro de instituciones militares y las Asociaciones Económicas de Amigos del País jugaron un papel importante en la renovación y difusión de las ciencias. La Monarquía protegió e impulsó la apertura de este tipo de instituciones durante todo el siglo, como lo demuestran la constitución de la Real Academia de Lengua (1713), la Real Academia Militar de Matemáticas (1716) la Academia de Guardiamarinas de Cádiz (1717), la Real Academia de la Historia (1738), el Observatorio Astronómico en Cádiz (1753), el Colegio de Cirugía de Cádiz (1748), el Real Jardín Botánico de Madrid (1755), las Academias de Guardiamarinas de Ferrol y Cartagena (1776), la Real Sociedad Bascongada de Amigos del País (1765) y la Matritense (1775), modelos seguidos por las numerosas sociedades de amigos del país que proliferaron en la península en las últimas décadas del setecientos, por mencionar sólo unos pocos ejemplos destacados.

Además, junto a la apertura de estas instituciones especializadas, la Monarquía financió el envío de pensionarios al exterior para formarse en los avances científicos de la época, de modo complementario a sus esfuerzos para incorporar en sus centros de formación a profesores y técnicos extranjeros de reconocida trayectoria. Si bien este tipo de políticas sufrieron altibajos en el transcurso de la centuria, relacionados con las coyunturas bélicas y la disponibilidad de recursos de la Real Hacienda, tuvieron una cierta continuidad en los diferentes reinados, desde Felipe V a Carlos IV. De este modo, como ha sostenido Domínguez Ortiz, el impulso científico fue posible -ante las dificultades de una profunda reforma universitaria- en instituciones técnicas. Debido a que las universidades eran reticentes a formar matemáticos, físicos, metalurgistas, astrónomos, cartógrafos, botánicos, etc. que necesitaba la Monarquía para profesionalizar el Ejército y la Marina, mejorar sus explotaciones mineras y otras actividades fundamentales dentro de sus territorios, se preocupó por buscarlos en el exterior y por crear centros especializados en sus posesiones, comenzado por la península. ${ }^{8}$

\footnotetext{
${ }^{7}$ Peset, Manuel y Peset, José L.; “La renovación universitaria”; en Sellés, Manuel; Lafuente, Antonio y Peset, José Luis (comps.); Ob. Cit.; p. 143 y ss.

${ }^{8}$ Domínguez Ortiz, Antonio; Carlos III y la España de la Ilustración; Alianza; Madrid; 2005; p. 267 y ss.
}

178

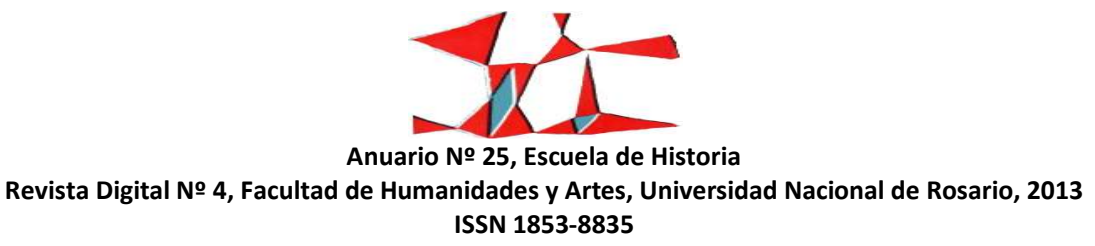


Fue en el ámbito militar donde se concretaron las primeras reformas, uno de cuyos objetivos buscó la asimilación de prácticas científicas. La transformación del aparato militar se inscribió entre las prioridades de Felipe V desde su llegada a España a comienzos del siglo XVIII. Las necesidades de la Guerra de Sucesión jugaron a favor de los cambios, a lo que se sumaron las urgencias de defender y preservar la totalidad de la herencia recibida. La modernización militar debía acompañarse con un reforzamiento de las competencias científicas, asevera Galland Seguella, ante el convencimiento de que científicos y técnicos eran cada vez más necesarios en el arte de la guerra. ${ }^{9}$

Así, desde comienzos del setecientos se trató de estimular la instrucción de los militares en "disciplinas útiles" para su mejor desempeño al servicio de la Monarquía. Con ese objetivo, Felipe V erigió en 1716, en Barcelona, la Real Escuela Militar de Matemática y el Cuerpo de Ingenieros, dotándolos de unas precisas instrucciones que fueron modificadas en 1739 y en 1751, bajo el reinado de Fernando VI. La introducción que antecedía al Reglamento de la Academia Militar de Matemáticas de 1751 sostenía:

Acreditando la experiencia quánto conduza al mayor acierto en las operaciones Militares el deleitoso estudio, y conocimiento de las Ciencias Mathematicas, y especialmente aquellas, que conciernen al Arte de la Guerra, por lo mucho que contribuyen sus fundados preceptos, y invariables reglas en los diferentes Ramos, y casos de la ofensiva, y defensiva, además de las copiosas utilidades, que en la Paz subministran sus noticias para el comun beneficio de mis Vasallos; y considerando, que el medio mas oportuno para conseguir esta importancia, es el cuidado de instruir en Escuelas, ó Academias formales de esta Ciencia á los mismos individuos del Exercito desde su juventud, por Professores Militares, que como tales, sepan elegir las materias conducentes al intento, y les puedan comunicar en su explicación á los discipulos las reglas de la verdadera aplicación de sus preceptos en la práctica; [...]. ${ }^{10}$

\footnotetext{
${ }^{9}$ Galland Seguela, Martine; “Los ingenieros militares españoles en el siglo XVIII”; en Cámara Muñóz, Alicia (coord.); Los ingenieros militares de la Monarquía Hispánica en los siglos XVII y XVIII; CEEH; Madrid; 2005; p. 205.

${ }^{10}$ Reglamento, ordenanza e instrucción de S.M. para la subsistencia, regimen y enseñanza de la Real Escuela, ó Academia Militar de Mathematicas, establecida en Barcelona, las particulares en Orán, y Ceuta, unas, y otras al cargo, y direccion del Cuerpo de Ingenieros, para la enseñanza de los Oficiales y Cadetes del Exercito. Madrid: Antonio Marin, 1751.
}

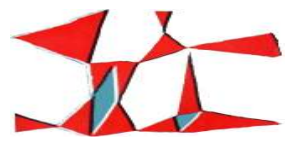

Anuario № 25, Escuela de Historia 
Las palabras anteriores subrayan la noción de estimular el estudio de las matemáticas, las que se presentaban como la base de la ciencia militar. ${ }^{11}$ Hay períodos en los que dicha noción apareció con más fuerza y se trasuntó en acciones concretas que favorecieron el arraigo de su estudio. Uno de esos momentos se verificó bajo el influjo del todopoderoso Marqués de la Ensenada, en los años centrales del siglo -un claro ejemplo lo encontramos en el Reglamento antes mencionado-, y continuó después con el favor y la protección de algunos de los ministros de Carlos III.

Estas inquietudes también se trasladaron al campo colonial, en la segunda mitad del siglo. Así, en el virreinato del Río de la Plata, el Consulado de Comercio -creado en 1794, al frente del cual estuvo Manuel Belgrano desde sus comienzos- fue la principal institución que canalizó el fomento de la ciencia y sus aplicaciones al ámbito militar, aunque también orientó estos saberes al terreno económico, en especial la agricultura, el comercio y las manufacturas. A su cargo corrió la difusión de la matemática aplicada, una de las columnas vertebrales de la instrucción científica en la capital virreinal. Fue Belgrano quien promovió esta ciencia a la que consideraba como fundamento del comercio, la navegación, la agricultura, la industria y el conocimiento del territorio. Éste es un ejemplo de la correlación entre el camino seguido en la península y en los espacios ultramarinos, en cuanto a estimular la ciencia entendida como matriz de las actividades productivas, antes que limitarse a un discurso teórico o especulativo sobre la naturaleza. ${ }^{12}$

\section{Apuntes sobre la vida de Sourrière de Souillac}

Los pocos datos biográficos que se difundieron de la vida de Sourrière los expuso De Angelis en la introducción con la que este historiador prologó los escritos de Sourrière en su Colección de documentos, ya mencionada. En esa ocasión afirmó que el matemático había nacido en 1750 en la ciudad de Ciotat -un pequeño puerto mediterráneo entre Tolón y Marsella- y que se había exiliado en España siendo muy joven, como consecuencia de un duelo en el que había muerto su oponente. Una vez instalado en Galicia, Sourrière había sido admitido en el astillero del Esteiro, en calidad de maestro de los aprendices delineadores. Más tarde hubo de ocupar la cátedra de matemáticas de la Academia Naval del Ferrol. En

\footnotetext{
${ }^{11}$ Capel, Horacio; Sánchez, Joan E. y Moncada, Omar; De Palas a Minerva: la formación científica y la estructura institucional de los ingenieros militares en el siglo XVIII; Serbal; Madrid; 1988; p. 234.

${ }^{12}$ Asua, Miguel; La ciencia de Mayo: la cultura científica en el Río de la Plata, 1800-1820; FCE; Buenos Aires; 2010; pp. 21-23. El libro contiene una muy buena síntesis de los puntos centrales del desarrollo científico en el virreinato del Río de la Plata, desde la década de 1790.
}

180

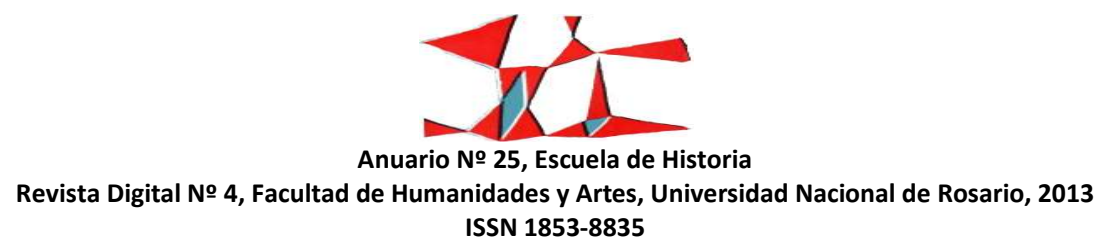


1773 Sourrière ya se encontraba en Buenos Aires, donde desempeñó diferentes actividades, siempre relacionadas con la matemática, por caso allí abrió una escuela para enseñar dicha ciencia. También fue miembro integrante de la Tercera Partida de demarcación de Límites que se dirigió a la región de Santa Cruz de la Sierra, en el Alto Perú. En su viaje hacia aquel destino, pasó por la ciudad de Córdoba, cuyo derrotero anotó en el ya mencionado "Itinerario". En el transcurso de esa misión oficial y una vez allá realizó trabajos de arquitectura en la Villa de Potosí y Cochabamba; ${ }^{13}$ también recorrió toda la provincia de Chiquitos, expedición de la que dejó testimonio en una extensa descripción. Volvemos a encontrar a Sourrière en una actividad oficial en 1805, cuando el Virrey Marqués de Sobremonte le encomendó explorar un paso por la Cordillera de los Andes que uniese Buenos Aires con Chile. Sourrière pasó los últimos años de su vida en esa ciudad, donde falleció en 1820.

Los datos que proporcionó De Angelis en su colección documental fueron recogidos por autores posteriores, entre ellos algunos diccionarios biográficos, que recuperaron la información consignada por el publicista napolitano, aunque sin añadir otras referencias destacadas que ayudasen a conocer mejor la trayectoria de este matemático en el virreinato. Un aspecto compartido por los autores que utilizaron como referencia los datos consignados por De Angelis es el énfasis puesto sobre la destacada tarea que había concretado Sourrière con la exploración del camino por la Cordillera de los Andes para unir Buenos Aires con Chile.

En el siglo XIX, la figura de Sourrière fue recuperada en algunos textos dedicados a la historia del Río de la Plata y a la enseñanza de las ciencias en estas latitudes. W. Parish, un diplomático británico que vivió en Buenos Aires en las décadas de 1820 y 1830, incluyó una referencia a las actividades de Sourrière en su libro Buenos Aires y las provincias del Río de la Plata. En ese texto, recuperó los aportes de éste al mejor conocimiento de los territorios rioplatenses, al dejar asentado el camino que éste recorrió entre Buenos Aires y Córdoba y su tarea al descubrir el paso cordillerano hacia Chile, conocido como el paso de las Damas de Sobremonte. ${ }^{14}$ Por su parte, una escueta alusión a la labor educativa de Sourrière como responsable de la

\footnotetext{
${ }^{13}$ De acuerdo a Capel, estuvo a cargo de la construcción del cuartel proyectado por Juan del Pino Manrique en la villa de Potosí. Capel, Horacio; Los ingenieros militares en España, siglo XVIII. Repertorio bibliográfico e inventario de su labor científica y espacial; Universitat de Barcelona; Barcelona; 1983; p. 455.

${ }^{14}$ Parish, Woodbine; Buenos Aires y las Provincias del Río de la Plata. Desde su descubrimiento y conquista por los españoles; Benito Hortelano imprenta; Buenos Aires; 1852; pp. 248-250, traducción de Justo Maeso. La primera edición del texto, en inglés, fue
}

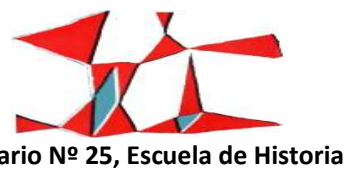


apertura de una escuela de matemática, fue incorporada por José M. Gutiérrez en un trabajo que indagaba acerca de la enseñanza pública en Buenos Aires luego de la expulsión de los jesuitas. ${ }^{15}$ Una mención semejante a la anterior fue realizada por L. Domínguez en su Historia Argentina, a la que adicionó la exploración que había hecho Sourrière en la provincia de Chiquitos, durante la expedición demarcadora de límites. ${ }^{16}$ También un estudioso chileno, Claudio Gay, remarcó la labor de Sourrière en la búsqueda de nuevas vías de comunicación entre Buenos Aires y Chile a fines de la etapa colonial. ${ }^{17}$

Los autores referenciados anteriormente apelaron a los datos expuestos por De Angelis para introducir breves comentarios sobre la vida de Sourrière. Los trabajos publicados en el siglo XX siguieron un camino semejante. En este caso, podemos mencionar a G. Furlong, E. Udaondo y H. Capel, quienes añadieron poca información nueva. ${ }^{18}$ Furlong realizó una síntesis de lo escrito un siglo antes por De Angelis, y consideró que Sourrière era agrimensor de profesión. Udaondo señaló que Sourrière efectuó importantes tareas de medición y demarcación topográfica en las costas de los ríos Paraná, Uruguay, Reconquista y Gualeguay -en el actual territorio de la provincia de Entre Ríos- entre los años 1776 y $1778 .{ }^{19}$ Capel sólo consignó el año de nacimiento y defunción de Sourrière, su paso por Ferrol y las labores que ejecutó relacionadas con su formación de ingeniero en Potosí (durante sus actividades en la Tercera Partida de Límites) y en la villa de Nueva Bilbao en Chile, cuando reconoció el camino cordillerano en 1805. Paralelamente, afirmó que no podía probarse que Sourrière se hubiese titulado como ingeniero militar.

publicado en Londres en 1839. Allí también Parish destacó que la publicación efectuada por De Angelis rescató del olvido las tareas desempeñadas por Sourrière.

${ }^{15}$ Gutiérrez, José Luis; Noticias históricas sobre el origen y desarrollo de la enseñanza pública desde la época de la extinción de la Compañía de Jesús en el año 1767 hasta poco después de fundada la universidad en 1821; Imprenta del siglo; Buenos Aires; $1868 ;$ p. 182.

${ }^{16}$ Domínguez, Luis L; Historia Argentina; C. Casavalles editor; Buenos Aires; 1870; p. 324.

${ }^{17}$ Gay, Claudio; Historia física y política de Chile según documentos adquiridos en esta republica durante doce años de residencia en ella y publicada bajo los auspicios del supremo gobierno; Museo de Historia Natural; Santiago de Chile; 1865; parte V; V. II; pp. 309310.

${ }^{18}$ Furlong Cardiff, Guillermo; Matemáticos argentinos durante la dominación hispánica; Huarpes; Buenos Aires; 1945; pp. 99-100, 145 y 162-163. Udaondo, Enrique; Diccionario biográfico colonial argentino; Huarpes; Buenos Aires; 1945; p. 858 y Capel Horacio; Los ingenieros...; Ob. Cit.; p. 455.

${ }^{19}$ Hemos encontrado dos referencias de Sourrière relativas a su desempeño en tareas de mensura. La primera, del año 1777 cuando un juez del cabildo de la ciudad de Santa Fe y Sourrière delimitaron y midieron varias estancias frente al río Paraná -entre los arroyos o parajes de Punta-Gorda y las Conchas- destinadas a ser vendidas. Véase Revista del Paraná. Historia. Literatura. Lejislación. Economía política ( $N^{\circ} 5$ año 1, 30 junio 1861); p. 244. La segunda mención corresponde al año de 1779 y presenta a Sourrière mensurando varias chacras en el partido de La Matanza. Bertune Fatgala, Mirta N.; "El antiguo partido de La Matanza (1778-1821)"; en Historia de La Matanza; Universidad Nacional de la Matanza; Buenos Aires; 2009; p. 28.

182

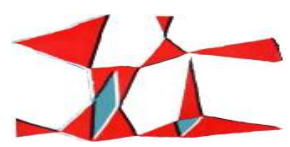

Anuario № 25, Escuela de Historia

Revista Digital № 4, Facultad de Humanidades y Artes, Universidad Nacional de Rosario, 2013 ISSN 1853-8835 
De hecho, la información que había proporcionado De Angelis no deja de ser muy general y además, contiene algunas inexactitudes. Por caso, el propio Sourrière afirmó en su testamento, redactado a fines de 1818, que era natural de Marsella y que se había naturalizado en "estos países de la América del sud", en alusión a lo que había sido el antiguo virreinato del Río de la Plata. ${ }^{20}$ Su origen marsellés también lo había aseverado en el diario del viaje para la apertura del camino cordillerano a Chile: "Esto es por ahora lo que presento á los Padres de mi amada Patria (aunque de Marsella), prometiendo no perder oportunidad [...]."21

La formación y trayectoria de Sourrière contienen varias lagunas, aunque a partir de los documentos que hemos recuperado en el Archivo General de la Nación podemos ahora reconstruir mejor sus actividades. ${ }^{22}$ En primer lugar, vamos a detenernos en su formación científica. Sabemos que a fines de 1772 o principios de 1773, cuando Sourrière arribó a Buenos Aires, solicitó al entonces Gobernador General Juan José Vértiz autorización para abrir una Escuela de Matemáticas. ${ }^{23}$ Su pedido fue acompañado por tres certificados de autoridades del Departamento Naval del Ferrol, los que detallaban las actividades que él había desempeñado en ese puerto y astillero de la Monarquía: allí, en calidad de maestro de matemáticas había dictado lecciones de esa ciencia en la Academia de Arquitectura Naval, ${ }^{24}$ había enseñado matemática "y otras ciencias" en el Arsenal del Ferrol ${ }^{25}$ y había impartido aritmética y geometría a los aprendices delineadores en el Arsenal de Esteyro. ${ }^{26}$ Los documentos presentados como constancia están fechados en junio de 1771 y marzo de 1772, y en uno de ellos se especificaba que "cesa en su función por decisión propia y no porque hubiese sido despedido". Esa aclaración no colabora en explicar las razones que llevaron a Sourrière a abandonar Galicia y trasladarse a Buenos Aires, estando además ya casado y con un hijo. ${ }^{27}$ Podría pensarse que tenía conocidos en esta capital que lo instaron a emigrar, puesto que su formación

\footnotetext{
${ }^{20}$ Archivo General de la Nación Argentina (en adelante AGN), Sala IX, Tribunales, Sucesiones, Leg. 8144.

${ }^{21}$ AGN, Sala IX, Leg. 30-7-6, Exp. 2.

${ }^{22}$ AGN, Sala IX, Leg. 42-6-2, Exp. 16, Sala IX, Leg. 39-5-5, Exp. 1, Sala IX, Leg. 30-7-6, Exp. 2.

${ }^{23}$ Se toma como referencia la petición que Sourrière elevó al gobernador Vértiz, firmada en Buenos Aires el 18 de marzo de 1773. AGN, Sala IX, Leg. 42-6-2, Exp. 16, doc. 6.

${ }^{24}$ Certificado firmado por Joseph Romero, Ingeniero del Real Cuerpo de construcción de Marina y Theniente Coronel graduado, en Ferrol a 16 de junio de 1771. AGN, Sala IX, Leg. 42-6-2, Exp. 16.

${ }^{25}$ Certificado firmado por Francisco Segurola, Ayudante de Construcción en el Departamento de Ferrol, a 18 de junio de 1771 . AGN, Sala IX, Leg. 42-6-2, Exp. 16.

${ }^{26}$ Certificado firmado por Joseph Romero, en Esteyro a 24 de marzo de 1772. AGN, Sala IX, Leg. 42-6-2, Exp. 16.

${ }^{27}$ Sourrière estaba casado con María de la Concepción Bouzo y Sanjurjo, natural de Galicia, y su hijo se llamaba Francisco Agustín. Así lo indica en un pedido elevado al Alcalde de primer voto del Cabildo porteño. De acuerdo a su testamento, tuvo otros hijos pero todos, incluido Francisco, murieron siendo aún pequeños o muy jóvenes. AGN, Sala IX, Leg. 42-6-2, Exp. 16 y Sala IX, Tribunales, Sucesiones, Leg. 8144.
}

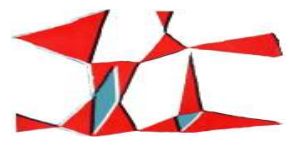

Anuario № 25, Escuela de Historia Revista Digital № 4, Facultad de Humanidades y Artes, Universidad Nacional de Rosario, 2013 ISSN 1853-8835 
podía ser muy bien recibida en estas latitudes. En otro documento escrito por Sourrière en septiembre de 1783, dirigido al Alcalde de primer voto del Cabildo porteño, sólo especificaba que se había desempeñado como maestro en Ferrol durante cuatro años, pero no las razones de su partida.

Con esas fechas podemos inferir, por un lado, que había llegado a España a mediados de la década de 1760, siendo muy joven, con dieciséis o diecisiete años, y que su formación profesional en matemática, geometría y otras disciplinas relacionadas debió transcurrir en Francia. Su rápida inserción en Ferrol pudo deberse, casi con seguridad, a sus conocimientos previos de esas ciencias, situación que se adecuaba a la política borbónica de incorporación de técnicos y científicos extranjeros para el desarrollo de las ciencias útiles en España.

El Departamento Naval del Ferrol, recientemente construido, se encontraba por esa época en expansión y era uno de los núcleos más activos de la industria naviera de la península, demandando una cantidad importante de profesionales formados. Es de señalar que en 1726 se había nombrado a Ferrol capital del Departamento Naval del Norte y que entre 1730 y 1735 se botaron allí los primeros buques para la Marina. Hacia 1740, se inició la construcción del nuevo arsenal, ubicado en la ribera oriental de la primitiva villa del Ferrol, en las inmediaciones del monte Esteiro; de allí su nombre. Luego, durante el reinado de Fernando VI, se trasladaron las oficinas desde Esteiro a Ferrol, expandiéndose rápidamente la actividad naval. Se estima que luego de mediados del siglo, unos quince mil obreros trabajaban en el Arsenal y en múltiples actividades relacionadas con la industria naval. De igual manera, la villa que en 1749 reunía 250 vecinos, asistió al crecimiento acelerado de su población y se convirtió en una de las más pobladas de Galicia. ${ }^{28}$ La situación privilegiada de Ferrol hace plausible que fuera un lugar atractivo para la instalación de jóvenes que poseían una buena formación científica, pues allí encontrarían trabajo con facilidad, situación que se verificó en el caso de Sourrière. Cabe señalar también que Ferrol fue sede de una de las Academias de Guardiamarinas que se estableció en 1776 -ya para esa época Sourrière se encontraba en Buenos Aires- junto con la de Cartagena, instituida el mismo año. Ambas se sumaron a la primer Academia que funcionaba en Cádiz desde 1717 en la formación de los cuerpos de oficiales de la Marina.

\footnotetext{
${ }^{28}$ Montero y Arótegui, José; Historia y descripción de la Ciudad y Departamento naval del Ferrol; Imprenta de Beltrán y Viñas; Madrid; 1859; pp. 63-69.
}

184

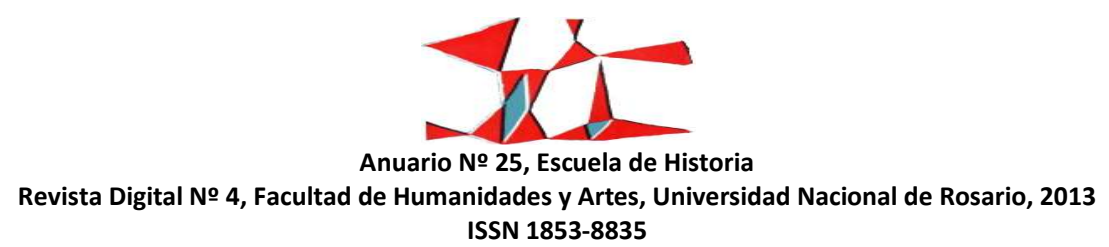


Se sabe, entonces, que la formación inicial de Sourrière era la propia de un profesor de matemática. ${ }^{29}$ En los certificados que traía consigo desde Ferrol y en los primeros documentos que escribió a Vértiz, Sourrière se presentó así como maestro de matemáticas. Su incorporación a la Tercera División en la expedición de límites fue en calidad de matemático, según consta en el oficio en que se le asignó una paga mensual de cuarenta y cinco pesos:

[...] Don Josef Sourriere de Souillac es por su aptitud uno de los sujetos destinados á la Demarcacion de Limites con estos dominios y los de Portugal en calidad de Matematico, y hallandose ya en esta capital sin otro destino que el de este servicio [...], se servira V.S. dar la orden conveniente para que se le asista como al referido con cuarenta y cinco pesos de suelo al mes como lo tenemos ordenado. ${ }^{30}$

Su nombramiento como astrónomo para servir en la Tercera División fue posterior, siendo efectuado por el Virrey Marqués de Loreto en noviembre de 1788. En este caso se trató de un cargo interino, ante la posibilidad de que fuesen designados otros científicos desde España para desempeñar ese mismo puesto:

[...] he elegido interinamente a Don José Sourriere de Souillac por primer astronomo de la Tercera División destinada por parte de España á la demarcacion de sus limites en estos dominios: Por tanto le nombro por primer Astronomo de dicha Tercera Divison con la expresada calidad de interino por si hubiese de ejercer el mismo cargo el Comisario que se sirva S.M. nombrar para ella: y declaro que en falta de este, de los Ingenieros y del Oficial Comandante de la Tropa de Escolta ha de recaer en el mismo Sourriere el mando de dicha Division. [...] Dado en Buenos Ayres a dies y nueve de noviembre de mil setecientos ochenta y ocho años. ${ }^{31}$

Más allá de los títulos, la sólida formación científica que poseía Sourrière fue corroborada en varias oportunidades desde su arribo a Buenos Aires. Un primer examen fue requerido por Vértiz, antes de autorizar la apertura de la Escuela de Matemáticas que aquel quería establecer. Concedido el permiso fue la

\footnotetext{
${ }^{29}$ Una vez ya en el Río de la Plata, los títulos que se arrogó fueron tomados de los nombramientos oficiales que recibió, pero no tenemos constancia de que hubiesen sido expedidos por alguna institución colegial o universitaria.

${ }^{30}$ Vértiz, 19 de junio de 1781. AGN, Sala 9, Leg. 42-6-2, Exp. 16, doc. 11.

${ }^{31}$ AGN, Sala 9, Leg. 42-6-2, Exp. 16, doc. 1.
}

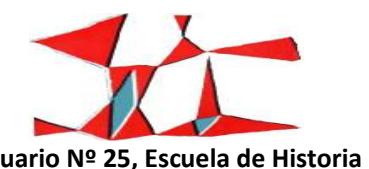


primera Escuela de matemáticas abierta en Buenos Aires. ${ }^{32}$ La condición que fijó el entonces gobernador fue que instruyese en esas ciencias, y sin cargo para la Real Hacienda, a dos oficiales de la tropa, los cuales serían destinados a tal fin.

Los encargados de verificar la idoneidad y formación de Sourrière fueron el Comandante del Real Cuerpo de Artillería, Francisco Betbeze, y el Capitán del Regimiento de Infantería, Félix de Yriarte. Ambos militares emitieron un informe en el que destacaban que:

[...] le consideramos mui capaz de poder abrir la escuela publica que solicita, aunque ignora la fortificacion, en que le será mui facil imponerse poseiendo como posee la Arithmetica, Geometrías, Calculos y demas materias conducentes al desempeño de su pretencion. ${ }^{33}$

Como planteaba el informe, Sourrière demostraba una buena formación, a pesar de que necesitaba instruirse en fortificación. Ese dato refuerza la suposición que expresamos anteriormente, de que este matemático había estudiado en Francia y había llegado a España ya titulado; caso contrario hubiese contado al menos con los rudimentos de la ciencia de la fortificación, puesto que el estudio de los principios de ésta era una preocupación de la Monarquía hispánica desde el Renacimiento.

Con relación a este tema, recordemos que Felipe II había fundado una Academia de Matemática, que formaba en esta disciplina. Durante todo el siglo XVII y comienzos del XVIII, la tarea de enseñar el arte militar había recaído en los jesuitas, en particular lo referente a la fortificación y la artillería, que se enseñaba en el Colegio Imperial de Madrid. Todos los cursos de matemática del siglo XVIII incluyeron, por tanto, una parte dedicada a la aplicación de los principios matemáticos en este asunto, que se llamaba "matemáticas mixtas". Por ejemplo, y siguiendo a Capel, Pedro de Lucuce-director de la Real Academia Militar de Barcelona desde 1738- sostenía que todos los alumnos debían instruirse en las nociones básicas de "fortificación regular" (líneas y ángulos de fortificación, escalas y medidas, máximas de los referentes más destacados en la materia), "fortificación irregular" (amurallamiento y defensa de perímetros no regulares y ciudades con diversa localización), "fortificación efectiva" sobre el terreno y "fortificación de campaña" (conocimientos sobre construcción de fuertes de campaña, diversas formas de atacar y de hacer

\footnotetext{
32 Domínguez, L.; Ob. Cit.; p. 324.

${ }^{33}$ AGN, Sala IX, Leg. 42-6-2, Exp. 16. El informe de los oficiales está fechado en Buenos Aires, a 28 de marzo de 1773.
}

186

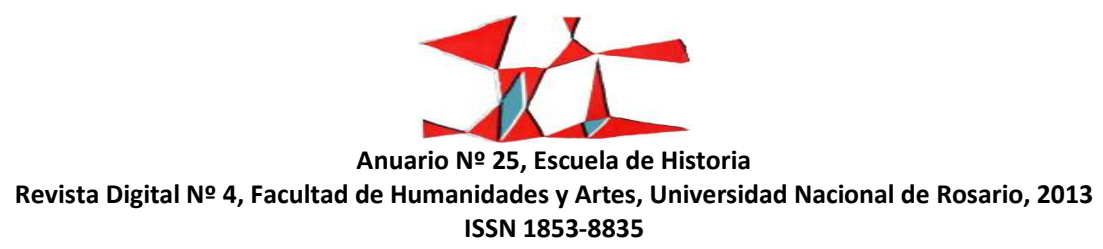


rendir una plaza, construcción de líneas de circunvalación y contravalación). ${ }^{34}$ En síntesis, si Sourrière se hubiera educado en España necesariamente habría adquirido este tipo de conocimientos.

Pocos años después, en 1778, el comandante Betbeze ratificó nuevamente la capacidad y solidez de Sourrière para enseñar matemáticas. En esa ocasión, el maestro había elevado al Virrey un requerimiento solicitando su admisión en alguno de los cuerpos del Ejército -en el Real Cuerpo de Artillería o en el de Dragones e Infantería-, ofreciéndose a cumplir no sólo las tareas asignadas a su cargo propio dentro del Ejército, sino también a enseñar matemáticas a los cadetes y oficiales. ${ }^{35}$ Este pedido de Sourrière permite suponer que la Escuela de Matemáticas no le proporcionaba los ingresos suficientes y que los alumnos asistentes eran pocos, si es que ésta continuaba abierta. Inclusive, si ejercía de manera privada como agrimensor -de acuerdo a lo indicado por Udaondo-, se desprende que necesitaba de otros ingresos para sí y su familia, razones que habrían motivado su pedido de ingreso al Ejército.

Al petitorio de admisión, Sourrière adosó un segundo escrito un mes después, fechado en 23 de mayo de 1778. Se trataba de un memorial dirigido al Virrey, en el que exponía los méritos que le habían sido reconocidos como matemático. Empero, el contenido más relevante del documento está dado por la justificación que hacía Sourrière de los beneficios de la instrucción de los cadetes en "ciencias útiles", para lo que citaba un libro recién editado en Madrid:

[...] y respecto de que en el tratado de Mathematicas que por disposicion y orden del señor Inspector General de Infantería compusieron el theniente coronel graduado don Geronimo Capmani y don Benito Bails, director de Mathematicas de la Real Academia de San Fernando para la dirección y uso de las Escuelas establecidas en los Regimientos de Infantería se advierte y dispone en su prologo que el estudio de las Mathematicas se debe unir en cada Regimiento con el de las Ordenanzas Militares destinando a este efecto un oficial inteligente é instruido que imponga la juventud en los principios y Reglas del Arte; no aviendo al presente en esta capital alguno oficial que este dedicado a este tan util como provechoso ejercicio por cuyo motivo los cadetes que empiezan a servir se hallen sin la Instrucción necesaria por el perfecto manejo del

\footnotetext{
${ }^{34}$ Capel, H.; De Palas a Minerva; Ob. Cit.; pp. 96-101 y 217-231.

${ }^{35}$ AGN, Sala IX, Leg. 42-6-2, Exp. 16.
} 
arma se ha de servir V.E atendiendo a la idoneidad en el suplicante y al servicio que ha hecho á el Departamento del Ferrol [...]..$^{36}$

Los argumentos ofrecidos por Sourrière acerca de los beneficios que ofrecían los estudios matemáticos a la instrucción de los militares respondían a los lineamientos que los Borbones habían fijado en la modernización de los cuerpos militares y navales, desde los primeros años del setecientos. Su propuesta de convertirse en maestro de los oficiales asentados en Buenos Aires se adecuaba y pretendía continuar la senda adoptada por la Monarquía en la península y en otros territorios del imperio en la formación de sus cuadros armados. Además, el propio Sourrière había participado en la ejecución de esas políticas de instrucción científica en los arsenales de Ferrol. Por ello, no sorprende que Sourrière reforzara su pedido mediante la cita de uno de los libros más importantes que se escribieron en España para atender a la instrucción en matemáticas de los cadetes de Infantería en la segunda mitad del setecientos: Tratados de Matemática. ${ }^{37}$

La redacción del texto anterior había sido solicitada expresamente por el entonces Inspector General y Teniente General de los Reales Ejércitos, el conde de O-Reilly, para las escuelas establecidas en los Regimientos de Infantería. De sus dos autores, el más conocido era Benito Bails, director de matemática de la Real Academia de San Fernando de Barcelona y responsable de introducir y adecuar la enseñanza de esa disciplina en las Artes, en especial la arquitectura. ${ }^{38}$ La primera edición data de 1772 , el mismo año en que Sourrière había abandonado la enseñanza en Ferrol para trasladarse a Buenos Aires.

El punto que interesa remarcar es cómo Sourrière se identificó con los objetivos señalados en esa obra y se presentó al Virrey como la persona idónea para conducir la instrucción de los soldados en el Río de la Plata. La justificación que ensayó en su escrito -citada anteriormente- exponía lo que Bails y Campany habían afirmado en el prólogo de su obra acerca del objetivo del Tratado:

\footnotetext{
${ }^{36}$ AGN, Sala IX, Leg. 42-6-2, Exp. 16. Sourrière concluye su argumentación afirmando que está animado por la firme voluntad de ser un fiel súbdito del rey y de contribuir con sus saberes a un mejor entrenamiento de los soldados. Agrega también el beneficio que obtendría de este puesto para mantener a su familia, "que la hizo venir de España con mucho costo".

${ }^{37}$ Bails, Benito y Capmany, Gerónimo; Tratados de Mathematica; Imprenta de Joachim Ibarra; Madrid; 1772.

${ }^{38}$ Benito Bails, natural de San Adriá de Besós, muy cerca de Barcelona, había nacido en 1730. Su formación transcurrió en las universidades francesas de Perpignan, Tolouse y París. En la capital francesa colaboró en la embajada de la corte española, desde donde fue recomendado a su regreso a España por su formación y méritos para la enseñanza. Fue autor de numerosas obras de matemáticas, que recibieron los elogios de personalidades destacadas del reformismo como el marino Jorge Juan. Fernández de Navarrete, Martín; Biblioteca marítima española; Imprenta de la Viuda de Calero; Madrid; 1851; T. I; pp. $227-230$.
}

188

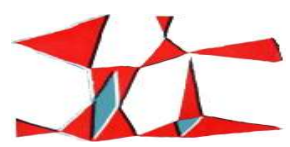

Anuario № 25, Escuela de Historia

Revista Digital № 4, Facultad de Humanidades y Artes, Universidad Nacional de Rosario, 2013 ISSN 1853-8835 
[...] proporcionar a la juventud destinada á las Armas la instrucción necesaria á todo Oficial en las partes de la Matemática de que trata, y facilitar á los aplicados las noticias convenientes para que puedan por sí adelantar sus conocimientos en la materia.

[...] Los Exércitos sin una exacta disciplina son poco temibles á los Enemigos: el valor y la obediencia, dirigidos por la ciencia, aseguran las victorias: las tropas de instruyen y forman en tiempo de paz: el valor y la constancia son siempre proporcionados á la confianza que inspiran á la Tropa la perfeccion y ventaja de su disciplina, y el talento y la pericia de sus gefes y oficiales." ${ }^{39}$

Aquí se ponía de manifiesto, de una manera muy clara, no sólo la obligación del estudio de matemáticas, sino que éstas constituían el fundamento imprescindible de la eficacia militar; o, en otras palabras, un requisito indiscutible del arte de la guerra.

A la obra de Bails pueden agregarse otros varios libros sobre las ciencias útiles, en su mayoría de matemática, fortificación, geometría y astronomía, disponibles en Buenos Aires. ${ }^{40}$ Gran parte de los manuales y obras referidas a las materias matemáticas reflejaban el aumento de la edición de textos, que tenía como fin la enseñanza científica en los cuerpos militares. El crecimiento se verificó luego de 1770 y se enmarcó en los esfuerzos conducidos para continuar con la modernización del Ejército, luego de la publicación de las Ordenanzas Generales, en $1768 .^{41}$

Además de los textos que existían en el Virreinato, Sourrière también poseía su biblioteca personal, con diferentes ejemplares. De acuerdo al inventario efectuado luego de su muerte, entre sus libros se contaba la Trigonometría española del padre Zaragoza ${ }^{42}$; la colección completa de nueve tomos escrita por

\footnotetext{
39 Bails, B. y Capmany, G.; Tratados...; Ob. Cit.; pp. 1-4. (Prólogo).

${ }^{40}$ La obra de Furlong Cardiff, ya citada, contiene numerosas referencias de los textos disponibles en el Virreinato sobre estas materias.

${ }^{41}$ Sobre este tema puede consultarse Capel, H.; De Palas a Minerva...; Ob. Cit.; pp. 238y ss.

42 José de Zaragoza (1627-1679), miembro de la Compañía de Jesús, realizó destacados aportes a la renovación matemática en España en la segunda mitad del siglo XVII. Formado en la Universidad de Valencia, llegó a ejercer la cátedra de matemática en el Colegio Imperial de Madrid, donde también ejerció como cosmógrafo y consejero científico y técnico del rey; también se destacó como observador astronómico y en la construcción de instrumentos científicos (Fábrica y uso de varios instrumentos matemáticos, 1675). Publicó varias obras de matemática orientadas a servir de textos de estudio, las cuales significaron un importante aporte pedagógico al pobre desarrollo que mostraba España para la época en esa disciplina. Navarro Brotons, Víctor; "Los jesuitas y la renovación científica en la España del siglo XVIII”; en Studia historica. Historia Moderna; Salamanca; N¹4; 1996; pp. 35-39.
}

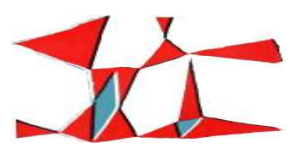

Anuario № 25, Escuela de Historia Revista Digital № 4, Facultad de Humanidades y Artes, Universidad Nacional de Rosario, 2013 ISSN 1853-8835 
el padre Tosca, el célebre Compendio Mathematico ${ }^{43}$; un ejemplar de los Elementos de Euclides; dos obras del reconocido profesor de matemáticas Sebastián Fernández de Medrano, El arquitecto perfecto en el arte militar y el Perfecto bombardero ${ }^{44}$; un ejemplar del Curso de Matemáticas escrito por Christian Wolff; tres tomos de las Observaciones astronómicas y phisicas del marino Jorge Juan. A los anteriores ejemplares se añadían varios libros de geografía, historia, filosofía, botánica y algunos diccionarios. ${ }^{45}$

Los libros mencionados formaban parte del compendio bibliográfico con el que se impartían lecciones de ciencias en las Academias, tanto en la península como en América. Además, hay dos autores que participaron de manera activa en lo que se llamó el movimiento de los novatores, el padre Zaragoza y el padre Tosca. Este movimiento fue articulándose en las últimas décadas del reinado de Carlos II y se proyectó hacia las primeras décadas del setecientos y en él los jesuitas tuvieron un papel destacado. Quienes participaron del mismo compartían el rechazo a la escolástica arraigada en las universidades españolas, pero también favorecieron la necesidad de comunicar los nuevos conocimientos, de compartir curiosidades, de mantener correspondencias con los partícipes de la République des Lettres, de reunirse en tertulias y academias, y de tener espacios de sociabilidad, de discusión y de difusión y fomento de los nuevos saberes. ${ }^{46}$ Entre los novatores se contaron varios miembros de la Compañía de Jesús. Es de señalar que los jesuitas fueron los principales impulsores de la renovación de los conocimientos científicos en España, en particular los relacionados con las matemáticas, a través de sus instituciones educativas; Madrid y Valencia fueron dos focos destacados en la introducción y difusión de los nuevos saberes a fines del

\footnotetext{
${ }^{43}$ Tomás Vicent Tosca i Mascó (1651-1723) tuvo una prolífica trayectoria como matemático, cosmógrafo, arquitecto y filósofo natural. Perteneció a la Congregación del Oratorio de San Felipe Neri y participó activamente del círculo de novatores de Valencia. Su Compendio Mathematico, publicado entre 1709 y 1715 (basado en el Cursus seu Mundus Mathematicus del jesuita francés Dechales, de 1690) fue el texto básico para profesores y alumnos aventajados de la Academia de Barcelona y de otras instituciones semejantes abiertas en la península en los primeros años del siglo XVIII. Capel, H.; De Palas a Minerva...; Ob. Cit.; p. 221 y Roselló, Vicenç M.; "Tomás V. Tosca y su entorno ilustrado en Valencia. Obra autógrafa y atribuciones”; en Ería; Oviedo; n64-65; 2004; p. 160.

44 Sebastián Fernández de Medrano se desempeñó como profesor y director de la Academia de Matemáticas de Bruselas, institución fundada a comienzos de la década de 1670. La instrucción impartida allí se orientaba a cuestiones prácticas antes que especulativas, siendo el objetivo más destacado el de formar expertos en arquitectura militar e ingenieros para las fronteras. En un informe de 1700, el propio Medrano justificaba el enfoque práctico y concreto de los estudios "huyendo de lo escolástico que se enseña en las universidades y seminarios". Capel, H.; De Palas a Minerva...; Ob. Cit.; p. 102.

${ }^{45}$ AGN, Sala IX, Tribunales, Sucesiones, Leg. 8144. Es importante señalar que al lado de cada libro inventariado se indicó el idioma en que estaba escrito. Así se encuentran obras en francés (lengua madre de Sourrière), castellano (lengua de adopción) y portugués. Muy posiblemente, Sourrière manejase también el latín, si nos atenemos a la formación teológica que en sus escritos afirmaba tener.

${ }^{46}$ López, François; "Los novatores en la Europa de los sabios"; en Studia historica. Historia Moderna; Salamanca; n¹4; $1996 ;$ p. 99.
} 190

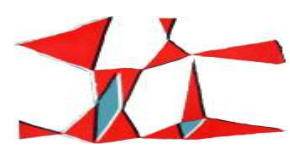

Anuario № 25, Escuela de Historia Revista Digital № 4, Facultad de Humanidades y Artes, Universidad Nacional de Rosario, 2013 ISSN 1853-8835 
seiscientos y los primeros años del setecientos. Asimismo, la existencia de algunos títulos relacionados con la fortificación y defensa, se muestran como un indicio de que Sourrière había aceptado las sugerencias recibidas cuando había sido evaluada su idoneidad por los dos integrantes del ejército.

Las actividades desempeñadas por Sourrière deben haber sido satisfactorias, ya sea en Buenos Aires como durante su participación en la Tercera Partida de Límites. No contamos con mayor información de otras tareas oficiales que le fuesen requeridas, más allá de breves referencia a algunas actividades de mensura que le encomendaron. ${ }^{47}$ Volvemos a encontrar a Sourrière en 1805 , cuando el Virrey Marqués de Sobremonte lo designó como geógrafo de la expedición para explorar un nuevo camino, que uniera Buenos Aires y Chile por la Cordillera de los Andes y le reconoció en esa oportunidad ese status. ${ }^{48}$ En el oficio, Sobremonte resaltó que confiaba "en su exacto desempeño de la parte facultativa que se le encarga." ${ }^{49}$ Los papeles que Sourrière firmó y envió a las autoridades durante esa misión comenzaban con un encabezado que recogía todos nombramientos logrados hasta allí y otros:

Ytinerario que ha formado el ingeniero geografo del descubrimiento del nuevo camino real de las Damas de Sobremonte, sin cordillera, y sin nieve, y puesto en practica por el mes de septiembre, día 27 de 1805 por el maestro de Mathematicas Don Jose Lazaro Jacinto Sourriere de Souillac, primer astronomo de la Tercera partida de Limites demarcadora y doctor en Sagrada Teología, comisionado para ello. ${ }^{50}$

Se advierte que este científico acumuló a lo largo de su desempeño diferentes nombramientos oficiales para desempeñarse en actividades que exigían un buen conocimiento de las ramas de la matemática -aritmética, geometría, cálculo, etc.- y de disciplinas vinculadas, caso de la astronomía y la geografía-cartografía. Sourrière fue incorporando a su trayectoria esos pergaminos, de manera que en 1805, cuando escribía al Virrey se preocupó por dejar constancia de ellos, sin olvidar cuál fue origen, pues su nombre iba precedido de su primera ocupación: maestro de matemáticas. Incorporó además la credencial

\footnotetext{
${ }^{47}$ Véase supra, nota $\mathrm{n}^{\circ} 14$

48 "Buenos Aires, enero 5 1805. Al Geografo Don Jopeh Sourriere de Souillac. Comisionandole en clase de tal geografo para la expedicion que ba a hacerse al reconocimiento es el camino de viudas de Talca." AGN, Sala IX, Leg. 35-5-5, Exp. 1.

${ }^{49}$ AGN, Sala IX, Leg. 35-5-5, Exp. 1.

${ }^{50}$ AGN, Sala IX, Leg. 39-5-5, Exp. 1.
}

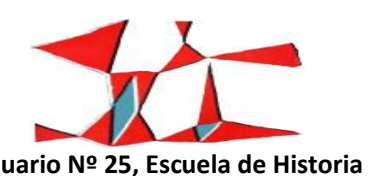


de ingeniero, aunque no tenemos constancia de un nombramiento en ese sentido. ${ }^{51}$ Desconocemos si luego de su arribo al Virreinato cursó alguna formación en teología, acorde al último título que hacía constar. ${ }^{52}$

En síntesis, puede advertirse entonces cómo Sourrière de Souillac, desde su paso por Ferrol y después, durante las casi cuatro décadas en que se desempeñó como matemático en el virreinato del Río de la Plata, trató de adecuar su formación y sus actividades a las exigencias de la Monarquía y de los proyectos reformistas que ésta encaró. Lo mismo puede decirse de las autoridades coloniales, que desde antes de la creación del Virreinato, también buscaron aprovechar las herramientas de que disponía el matemático para acompañar los cambios dictados en la península. El primer indicio que confirma esta orientación se puso de manifiesto en el mandato del gobernador Vértiz, cuando autorizó a Sourrière a abrir la Escuela en 1773, de instruir a dos oficiales en las disciplinas matemáticas. También la recomendación de los dos militares que examinaron al peticionante de familiarizarse con el estudio de las fortificaciones. La solicitud del propio Sourrière para incorporarse a un regimiento militar y desempeñarse como maestro de matemáticas, además de cumplir las tareas propias del cargo militar. Su pedido se encuadra dentro del esquema de militarización de la ciencia y de difusión de las disciplinas matemáticas como herramienta necesaria de cualquier militar, más allá de que las necesidades de dinero lo impulsaran a intentar incorporarse al Ejército.

La lectura que puede hacerse plantea que Sourrière, con los saberes adquiridos y ante posibles dificultades económicas personales, buscó insertarse en aquellas instituciones que podrían recibir con beneplácito sus conocimientos. La opinión de un miembro del Cabildo de Buenos Aires, en respuesta a un pedido de Sourrière para que la institución municipal ratificase la veracidad de sus papeles y sus méritos personales ante supuestas difamaciones que había recibido a su arribo a Buenos Aires, reforzaba esta idea:

[...] descubriendose en ellos [los documentos personales de Sourrière] un fondo considerable de merito que á acopiado el expresado Sourryere de Souillac en beneficio del Rey y de la patria: solo siente que este yndibiduo no aia continuado tan util e importante ministerio de maestro de matematicas, a toda costa se devia propender su continuación, porque sobre la llustración que

\footnotetext{
${ }^{51}$ Capel sostiene que no hay certeza que fuese ingeniero militar. Capel, H.; Los ingenieros...; Ob. Cit.; p. 455.

${ }^{52}$ Es la primera vez que aparece mencionado en alguno de los papeles que hemos localizado sobre su vida. Dentro del ámbito de las suposiciones, podría sugerirse que en su estancia en Córdoba o en alguna otra parte del virreinato asistió a alguna universidad que le hubiese concedido tal titulación.
}

192

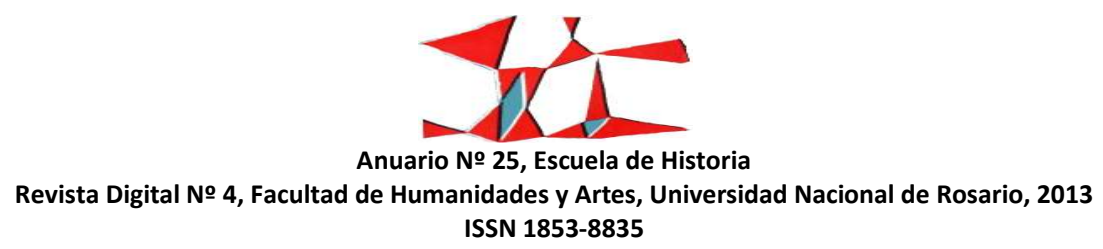


esta facultad ofrese á la Juventud en el dia son mas necesarias en esta capital los conosimientos de la fortificasion, geometria algebra y demas partes que comprenden sobre que el procurador general protesta asi representarlo a el expresado señor Virrey; [...]. ${ }^{53}$

El alcalde defendía los méritos del peticionante. Pero más notorio resultaba su parecer de la relevancia y aportes del saber matemático para una buena formación de los jóvenes, en consonancia con las políticas que venía desarrollando la Monarquía en sus territorios. Tan importante consideraba esa disciplina el alcalde, que prometía protestar ante la autoridad real para que se continuara con la enseñanza de las disciplinas matemáticas, probablemente porque la escuela iniciada por Sourrière no estuviese funcionando.

Para concluir, consideramos oportuno destacar algunas características de los escritos de Sourrière que hemos consultado, cuyo contenido permite ejemplificar cómo puso sus conocimientos científicos al servicio de la Monarquía, desempeñándose como funcionario borbónico. El manuscrito de referencia fue el diario que escribió del viaje completo desde Buenos Aires a Chile y viceversa y de las exploraciones que efectuó por la región de la ciudad de San Agustín de Talca y Nueva Bilbao. También consultamos -con los resguardos necesarios- el "Itinerario de Buenos Aires a Córdoba” que publicó De Angelis.

La información que Sourrière incorporó en sus textos no se limitó a cuestiones estrictamente matemáticas, de cálculo de distancias, a pesar de que éstas ocuparon una parte significativa de sus diarios. Respecto de los itinerarios seguidos y las mediciones efectuadas, organizó sus apuntes en cuadros muy detallados de distancias, en los que consignó el camino andado. En esos cuadros anotó el punto de partida y el de llegada, la distancia recorrida -expresada en leguas- y la demarcación de los lugares con la brújula, es decir, indica la dirección seguida para el traslado de un lugar a otro. Los nombres de los lugares corresponden a los utilizados por la gente local y que resultan conocidos; en algunos casos, como el trayecto del boquete del Atuel al cruzar la Cordillera, mencionó los topónimos en español y en lengua pehuenche.

Los apuntes técnicos los acompañó de comentarios personales relacionados con el estado de los caminos y las mejoras que deberían realizarse, cuando éstas eran requeridas para hacerlo transitable. Paralelamente, y en razón de sus conocimientos geográficos y también otros, como algunas nociones de

\footnotetext{
${ }^{53}$ AGN, Sala IX, Leg. 42-6-2, Exp. 16. Firmado por el alcalde de primer voto, Don Rivarola a 19 de septiembre de 1783.
}

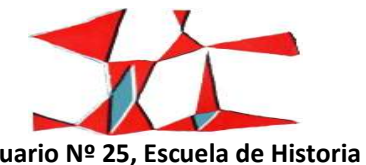


botánica, completó sus escritos con agudas observaciones de los paisajes que fue encontrando a su paso. Por ese motivo, añadió a los cuadros de los itinerarios extensas notas en las que daba cuenta de los recursos naturales y de las actividades económicas de quienes vivían en las regiones por las que pasó. Allí aprovechaba para reforzar algunas descripciones, explicar con detalle obras de infraestructura para mejorar un camino, construir puentes sobre cursos de agua, las calidades de las tierras y los cultivos que podían producir, etc.

Advertimos entonces que un rasgo constante en los escritos de este matemático fue la cantidad de detalles que incorporó, los cuales, a veces, desvían la atención del punto central que quería explicar. No obstante, su meticulosidad posibilitó que la representación que construyó este viajero de lo que observaba, pudiera ser aprehendida fácilmente por quienes leían sus informes. La preocupación de incluir el mayor número posible de pormenores lo llevó a emplear una abundancia de adjetivos con los que reforzaba su opinión y su presencia como autor en el propio texto.

En los análisis que incluyó en sus descripciones, Sourrière se muestra como un comprometido funcionario borbónico, conocedor de los proyectos políticos de la Monarquía. Cuando justificó, al final de su diario, la viabilidad del camino que había explorado, sostuvo que éste no sólo facilitaba las comunicaciones entre Chile y Buenos Aires sino también que resultaba una alternativa a la ruta marítima del Cabo de Hornos:

[...] la grandeza de este camino Real de las Damas, siempre que se verifique su utilidad, ahunque no sea mas que el precaver al Cabo de Hornos ó de San Antonio; pues con este descubrimiento practicable, arruinaremos en particular y en general los enemigos del Estado en el Mar Pacífico del Sur y se poblaran con mucha facilidad todos los terrenos que estan comprehendidos en las Pampas de Buenos Aires, y se enrrequeceran todos los Reynos del Perú con mucha facilidad y desasosiego $[\ldots]^{54}$

Las palabras de Sourrière permiten relacionar su expedición con el proyecto de viajes y exploraciones que impulsó la Monarquía en sus territorios en la segunda mitad del siglo XVIII. Una de las preocupaciones de la Corona, que tenía sus raíces en las postrimerías del siglo XVI, residía en que las potencias enemigas

${ }^{54}$ AGN, Sala IX, Leg. 39-5-5, Exp. 1.

194

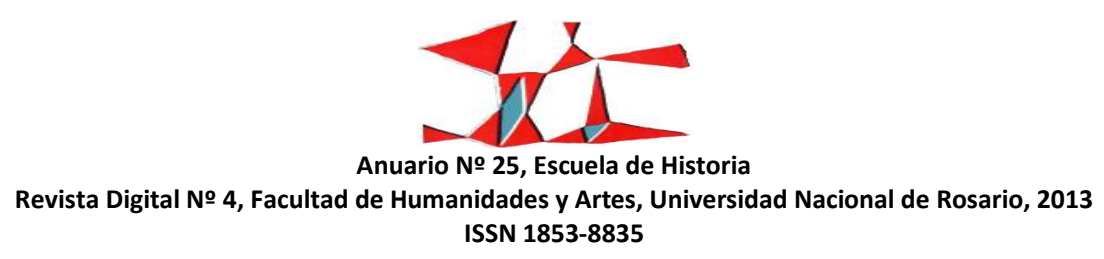


establecieran asentamientos en las costas del Atlántico austral, controlaran algún río navegable que desaguaba en del litoral patagónico y que tenía su origen en la costa de Chile o la Cordillera de los Andes hasta mediados del siglo XIX persistió la creencia de que había ríos navegables en la región patagónica que comunicaban los océanos-y desde allí se apropiasen de las minas argentíferas del Alto Perú. Esa fue una de las razones geopolíticas, entre otras más, que explican las numerosas expediciones que se dirigieron a la costa patagónica desde 1745 para explorar esos territorios, anudar pactos de amistad con las sociedades indígenas no sometidas y levantar poblaciones estables en la costa. El viaje de Sourrière para habilitar un nuevo paso por la Cordillera de los Andes se inserta dentro del ciclo de expediciones que impulsó con fuerza la Monarquía. Ya que si bien la finalidad principal era abrir un camino para el tránsito de carretas entre Buenos Aires y Chile, también se contempló su utilidad como paso de comunicación interoceánica en caso de que la ruta marítima del Cabo de Hornos estuviera en manos de algún enemigo de España.

También Sourrière defendió las políticas de la Monarquía relacionadas con el bien público. El ejemplo más nítido se encuentra en su proyecto de trasvasar agua del río Lontué, en las inmediaciones de San Agustín de Talca, mediante unos canales, hacia el río Claro, para hacerlo navegable; este último desembocaba en el gran río Maule, el cual desaguaba en el océano Pacífico. Sourrière estaba convencido de que era posible conectar por vía fluvial la ciudad de San Agustín de Talca con el océano Pacífico a la altura de villa de Nueva Bilbao, desde donde se podía llegar a los restantes puertos de Chile, del virreinato del Perú y también más al norte.

Su propuesta incorporaba numerosos argumentos con los que justificaba el interés público de esta obra. Cuando explicaba su proyecto de alimentar el curso del río Claro con el río Lontué, anteponía los beneficios generales que traería el mismo, por encima del perjuicio que podría ocasionar a unos pocos vecinos. Antes bien, la construcción de un canal serviría para disminuir el impacto de los desbordes e inundaciones, bastante frecuentes en la zona. Su opinión no estaba exenta de una ácida crítica de la corrupción pública, que favorecía a los potentados particulares por sobre los beneficios generales para la Monarquía:

[...] y solo quizas se le podra perjudicar á un vecino llamado Don Ignacio Zapata, el qual está dando principio a una azequia para dar agua á un molino para dar abasto de arina á la ciudad y á

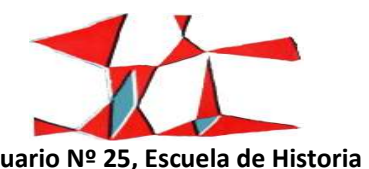


su comercio, el qual debe suspender dicha obra hasta tanto que su Magestad resuelve; pues no debe un vecino ser preferido á toda una República (lo que se acostumbra en el Perú, enrrequecer á uno para empobrecer á los demas porque tiene plata y es minero), pues que ella es la que sirve al soberano y según mi dictamen es acrehedor como un buen vecino y nada más. ${ }^{55}$

Las palabras anteriores muestran la cercanía de Sourrière con los postulados del reformismo borbónico sobre el bien público, al tiempo que se hacía eco de críticas que eran frecuentes, de las prácticas corruptas y los favoritismos. Lo interesante de sus dichos es el rechazo del trato favorable que disfrutaban las personas en función de su riqueza, lo cual perjudicaba al conjunto de la Monarquía. Su apreciación no iba contra los fundamentos de la sociedad de Antiguo Régimen, anclada en las desigualdades de status, ni contra la propia Monarquía. Por el contrario, en sus escritos defendía la autoridad real y entendía que sus actividades contribuían al mejor funcionamiento de la estructura monárquica. Su crítica se dirigió contra las prerrogativas que las personas con status y riqueza disfrutan en beneficio propio, perjudicando al conjunto, es decir, anteponiendo el interés personal al bien común.

\section{Palabras finales}

En este trabajo hemos ofrecido un acercamiento pormenorizado a la trayectoria de Joseph Sourrière de Souillac, maestro de matemáticas que, aunque francés de origen, pasó buena parte de su vida al servicio de la Monarquía Hispánica. Primero en la península, donde se desempeñó como maestro en el astillero del Ferrol; luego en el Virreinato del Río de la Plata, lugar en el que vivió casi medio siglo hasta su fallecimiento, ejecutando múltiples comisiones como matemático y geógrafo.

El acceso a documentos que contienen datos sobre su formación, actividades científicas y otros aspectos de su vida posibilitaron construir un cuadro más completo que el que se conocía hasta el momento: el que había transmitido Pedro De Angelis a mediados del siglo XIX. Los escritos de Sourrière contienen gran cantidad de apuntes que ayudan a conocer las tareas que desempeñó este matemático y viajero en el transcurso de sus exploraciones y misiones. Asimismo, la multiplicidad de noticias que consignó su autor permiten un mejor acercamiento para al estudio de diferentes realidades: geográfico-territoriales,

\footnotetext{
${ }^{55}$ AGN, Sala IX, Leg. 39-5-5, Exp. 1.
}

196

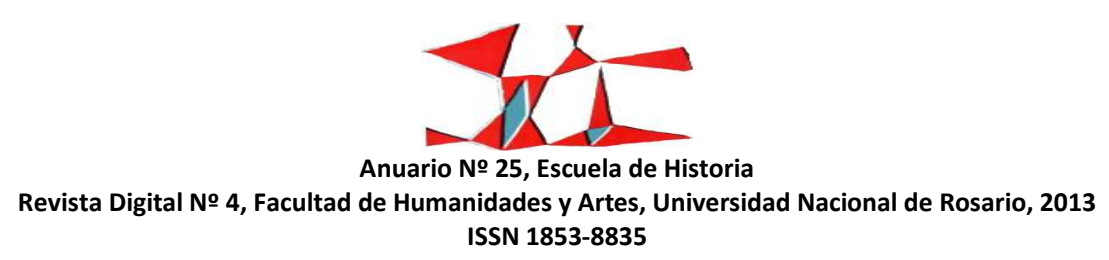


astronómicas, de recursos naturales, de los habitantes que habitaban los lugares recorridos, por mencionar sólo varias de las contenidas en los manuscritos de Sourrière.

La indagación acerca de la preparación en las disciplinas matemáticas que poseía Sourrière y su buen desempeño en la enseñanza de ellas, permite así insertarlo dentro de un contexto ampliado, en el que la promoción y desarrollo de las "ciencias útiles" constituyó uno de los pilares del reformismo borbónico durante el siglo XVIII. Su traslado voluntario a Buenos Aires desde Galicia y su incorporación en expediciones oficiales a raíz de sus saberes matemáticos, permite encuadrarlo dentro de los proyectos borbónicos de alcance imperial y de la urgencia de contar con técnicos especializados para cumplir misiones específicas, en las que las herramientas matemáticas resultaban indispensables, como muestra la trayectoria de la vida de este personaje.

Recibido: 19 de septiembre de 2013 Aprobado: 13 de noviembre de 2013 Versión final: 29 de noviembre de 2013 